\title{
Instability Condition Derivation for Hydraulic AGC System under Pressure Closed-Loop Control
}

\author{
Yong Zhu $\mathbb{D}^{1,2,3}$ Guangpeng Li, ${ }^{1}$ Shengnan Tang $\mathbb{D}^{1},{ }^{1}$ Wanlu Jiang $\mathbb{D}^{4},{ }^{4}$ Pengfei Qian, ${ }^{1}$ \\ Zhi Zheng, ${ }^{5,6}$ and Zhijian Zheng ${ }^{3}$ \\ ${ }^{1}$ National Research Center of Pumps, Jiangsu University, Zhenjiang 212013, China \\ ${ }^{2}$ State Key Laboratory of Fluid Power and Mechatronic Systems, Zhejiang University, Hangzhou 310027, China \\ ${ }^{3}$ Ningbo Academy of Product and Food Quality Inspection, Ningbo 315048, China \\ ${ }^{4}$ Hebei Provincial Key Laboratory of Heavy Machinery Fluid Power Transmission and Control, Yanshan University, \\ Qinhuangdao 066004, China \\ ${ }^{5}$ College of Mechanical Engineering, North China University of Science and Technology, Tangshan 063210, China \\ ${ }^{6}$ HUIDA Sanitary Ware Co., Ltd., Tangshan 063000, China
}

Correspondence should be addressed to Shengnan Tang; tangsn6635@126.com and Wanlu Jiang; wljiang@ysu.edu.cn

Received 3 December 2020; Revised 1 May 2021; Accepted 25 May 2021; Published 14 June 2021

Academic Editor: Zengshun Chen

Copyright (c) 2021 Yong Zhu et al. This is an open access article distributed under the Creative Commons Attribution License, which permits unrestricted use, distribution, and reproduction in any medium, provided the original work is properly cited.

In strip rolling, hydraulic automatic gauge control (HAGC) system is the key element to guarantee the precision of strip gauge. The stability of the kernel pressure closed loop (PCL) in the HAGC system plays an essential role in guaranteeing the rolling process with high performance. Nevertheless, there is some difficulty in exploring the instability mechanism of the HAGC system due to the fact that the PCL is a representative nonlinear closed-loop control system. In this work, for each component of the HAGC system, the mathematical model was established. And on the basis of the linking relation of various elements, we derived the incremental transfer model of the PCL system. Furthermore, in accordance with the deduced information transfer relation, the transfer block diagram of disturbing variable of the PCL system was obtained. Moreover, for the purpose of deriving the instability condition of the PCL system, the Popov frequency criterion was employed. The instability conditions of the HAGC system were obtained under PCL control. Furthermore, the derived instability conditions of the HAGC system were experimentally verified under various working conditions. The research results provide a fundamental foundation for studying the instability mechanism of the HAGC system.

\section{Introduction}

In the rolling industry, hydraulic automatic gauge control (HAGC) system is a pivotal component to guarantee the precision of strip thickness. The reliability of its work is the kernel of ensuring the rolling process with stabilization. Once the system fails, the downtime will occur or the quality of products will be greatly influenced [1-3]. More seriously, the entire production line will be paralyzed, which will result in huge economic losses. However, mass production practices show that there are frequently some interference factors or parameter variations in the work of rolling mill. When the HAGC system is disturbed by the disturbing force in the stable rolling process, the intrinsic balance relationship of forces will be damaged and the chattering phenomenon will occur $[4,5]$. The vibration of the HAGC system will lead to the bright and dark chatter mark on the surface of the rolled strip (as shown in Figure 1), which affects the accuracy of rolling. When the vibration is severe, it will also bring about problems such as strip breakage and steel-heaping and even cause production suspension and equipment damage in serious cases [6-8]. Therefore, for the rolling production process, it is urgent to thoroughly investigate the instability mechanism of the HAGC system and take effective control measures in real time. 


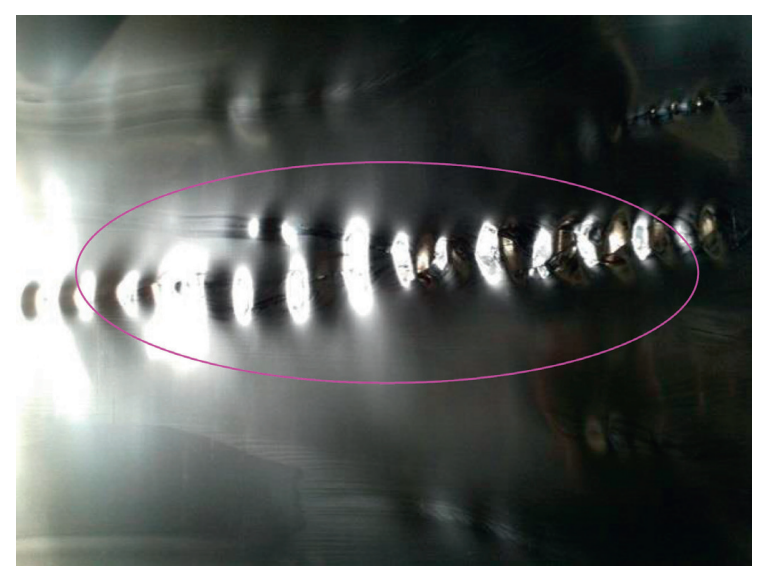

FIgURe 1: Photos of chatter mark on the strip surface.

The HAGC system is an intricate dynamic system formed by mechanical, electrical, and hydraulic elements. It has the features such as nonlinear, time-varying, strong coupling, and large hysteresis. The existence of multivarious interference elements makes it hard to research the instability mechanism of the HAGC system $[9,10]$. Currently, many researchers both domestically and overseas have been committed to the vibration characteristics and instability mechanism of rolling mill. The models for the third octave chatter of vibrational instability during rolling were presented and discussed by Meehan [11]. Niroomand et al. [12] introduced wave propagation theory to explain chatter mechanism in tandem cold rolling mills. Kapil et al. [13] used finite-element method to develop the kinematic equation of a four-high rolling mill and research the oscillation of working roll under various parameters. Fan et al. [14] developed the single degree of freedom (DOF) model of vertical vibration system of the F3 mill rollers, and some hysteretic features of rolled strip were further investigated. Zhang et al. [15] researched the electromechanical coupling resonance of the main drive system of mill, the cycloconverter and the synchronous motor were modeled and simulated by the matrix and laboratory (MATLAB)/Simulink, and then the natural characteristics of the mechanical drive system were calculated by ANSYS. Zeng et al. [16] established a coupling vibration structure model through analyzing the features of vertical or torsional vibrations. The effects of initial thickness and rolling reduction on thickness fluctuation were researched by Wang et al. [17]. Huang et al. [18] investigated the effects of asymmetric structure parameters on the stability of rolling mill via the numerical approach. Ji [19] studied the chatter in cold rolling mill in view of the interaction among vertical or torsional vibrations of upper work roll and longitudinal oscillation of rolled strip. A time-varying criterion was developed to estimate the stabilization of tandem cold rolling mill by Lu et al. [20]. By using the Routh-Hurwitz determinant and Hopf bifurcation theorem, the bifurcation features of mill vibration system were researched [21]. Chen et al. [22] presented a novel hybrid aeroelastic-pressure balance (HAPB) technique for measuring unsteady aerodynamics on a Pentium prism. Mannini et al. [23] researched the interference between vortex-induced vibration (VIV) and lateral degree of agreement in a wind tunnel. Chen and Tse [24] implemented an improved method for the physical nonlinearity of the weakly nonlinear spring suspension system, which is successfully used in the HAPB system. Wang et al. [25-27] investigated the effects of exciting forces on pump oscillation. The influences of key elements such as valve on system stability were studied by Qian et al. [28-30]. Zhang et al. explored the influence law of spring stiffness on pump motion via analyzing the coupling characteristics of pump and plunger motion based on dynamic grid and UDF method [31]. Wu et al. probed into the variation of pressure pulsation in pump under different flow conditions [32]. Wang et al. [33-35] and Bai et al. [36-39] studied the pump vibration under several statuses. Based on linear matrix inequality and Lyapunov-Krasovskii stabilization theory, Mobayen and Tchier [40] proposed a feedback control method with good transient performance. Moreover, Mobayen [41] proposed an adaptive global terminal sliding mode control method and proved its effectiveness and applicability via numerical simulation. Mobayen [42] also constructed a controller, which is helpful for the stability and robustness of the system. According to structural flexibility, the control strategy of the hydraulic shaking table was researched by Zhang et al. [43]. Lots of the above scholars have carried out many useful researches, which can provide theoretical direction for the further analysis on oscillation mechanism of rolling mill. However, there are still some problems. The effect of the HAGC system is usually neglected by most of research results when the oscillation mechanism of rolling mill is investigated. The instability mechanism of the HAGC system on the oscillation of rolling mill is rarely observed in-depth.

Formerly, the Lyapunov method was often adopted by scholars to research the absolute stability of nonlinear closed-loop system. Hua and $\mathrm{Yu}$ [44] gave a rigorous verification by utilizing Lyapunov stability theory to obtain the exponential stability of HAGC. Liu et al. [45] studied regenerative chatter mechanism in rolling through stability analysis by using integral criterion and Lyapunov method. Ding and Zheng [46] developed the explicit feedback controller for a nonlinear multiple-input affine system by assuming that a control Lyapunov function exists. Liu et al. [47] utilized Lyapunov analysis to verify the stability in finite time of closed-loop sliding mode control system. Zhang et al. $[48,49]$ used the Lyapunov functions to restrict the state variables to enhance the performance of nonlinear system. However, this Lyapunov method is a sufficient condition for evaluating the system stability, so it possesses certain conservatism. It is difficult to establish the required Lyapunov function in application. Until 1960, a frequency discrimination method was proposed to distinguish the absolute stability of nonlinear closed-loop system by Popov V.M. This method can depend on the classical transfer function and break away the predicament of rebuilding decision function. It represents a high application value [50]. The HAGC system is a representative nonlinear closed-loop system with various influencing factors. The instability vibration of the HAGC system may be produced in certain working status 
[51-53]. Hence, it is very significant to investigate the instability mechanism of the HAGC system from origin. It is a novel research way to theoretically deduct the instability mechanism of HAGC via utilizing the Popov criterion, which needs an in-depth study.

In this study, three important contributions are as follows:

(1) The mathematical model of the HAGC system is established. The incremental transfer model of the key pressure closed loop (PCL) in HAGC is deduced. Moreover, the transfer block diagram of the perturbation of the PCL system is instituted.

(2) The Popov criterion method is employed to derive the instability condition of the pivotal PCL system in HAGC. The instability mechanism of the HAGC system on the oscillation of rolling mill is observed in-depth.

(3) The derived instability conditions of the HAGC system are experimentally verified under various working conditions. The research results lay a fundamental foundation for the investigation on the instability mechanism of the HAGC system.

In the work, the contents of the article are arranged as follows. Firstly, the mathematical model of the PCL system is instituted in Section 2. Secondly, the incremental transfer model of the PCL system is derived in Section 3. Thirdly, the absolute stable frequency criterion for nonlinear closed-loop system is introduced in Section 4. Further, the instability condition for the PCL system is derived in Section 5. Finally, conclusions are obtained in Section 6.

\section{Mathematical Model of the PCL System}

In order to be readable, the nomenclature that includes all the used variables in this paper is summarized as follows:

Nomenclature

$T_{d}$ : time constant of differential

$T_{i}$ : time constant of integral

$K_{p}$ : proportionality factor

$s:$ Laplacian

$K_{a}$ : amplification coefficient, A/V

$U$ : input voltage, $\mathrm{V}$

I: output current, A

$x_{v}$ : spool displacement, $\mathrm{mm}$

$Q_{L}$ : load flow, $1 / \mathrm{min}$

$W$ : area gradient of valve port, $\mathrm{m}$

$C_{d}$ : flow factor of valve port

$p_{s}$ : supply pressure, $\mathrm{MPa}$

$p_{t}$ : return pressure, $\mathrm{MPa}$

$p_{L}$ : operating pressure of rodless chamber, $\mathrm{MPa}$

$\rho$ : density of hydraulic oil, $\mathrm{kg} / \mathrm{m}^{3}$

$I_{c}$ : input current, A
$K_{s v}$ : amplification factor of spool displacement on input current, $\mathrm{m} / \mathrm{A}$

$\omega_{s v}:$ specific angular frequency of servo valve, $\mathrm{rad} / \mathrm{s}$

$\xi_{s v}$ : damping factor of servo valve, N.s/m

$I_{N}$ : rated current of servo valve, $\mathrm{A}$

$x_{1}$ : displacement of piston rod, $\mathrm{mm}$

$A_{p}$ : valid working area of piston, $\mathrm{m}^{2}$

$C_{e p}$ : coefficient of external leakage, $\mathrm{m}^{3} \cdot \mathrm{s}^{-1} \cdot \mathrm{Pa}^{-1}$

$C_{i p}$ : coefficient of internal leakage, $\mathrm{m}^{3} \cdot \mathrm{s}^{-1} \cdot \mathrm{Pa}^{-1}$

$p_{b}$ : operating pressure of rod chamber, $\mathrm{MPa}$

$\beta_{e}$ : bulk modulus of oil, $\mathrm{MPa}$

$V_{0}$ : incipient volume of control chamber, $\mathrm{m}^{3}$

$m_{1}$ : equivalent mass of moving elements of upper roll system (URS), $\mathrm{kg}$

$m_{2}$ : equivalent mass of the moving elements of lower roll system (LRS), kg

$x_{1}$ : displacement of URS, mm

$x_{2}$ : displacement of LRS, $\mathrm{mm}$

$c_{1}$ : linear damping coefficient of moving elements of URS, N.s/m

$c_{2}$ : linear damping coefficient of moving elements of LRS, N.s/m

$k_{1}$ : linear stiffness coefficient between upper frame beam and moving elements of URS, N/m

$k_{2}$ : linear stiffness coefficient between lower frame beam and moving elements of LRS, N/m

$A_{b}$ : effective operating area of piston of rod chamber, $\mathrm{m}^{2}$

$F_{L}$ : load force acting on roll system, $\mathrm{N}$

$K_{f}$ : amplification coefficient, $\mathrm{V} / \mathrm{Pa}$

$T_{f}$ : time constant of pressure sensor

$Q_{L A}$ : the value of load flow at the working point A, $1 /$ $\min$

$p_{L A}$ : the value of working pressure at point $\mathrm{A}, \mathrm{MPa}$

$x_{v A}$ : the value of spool displacement at point $\mathrm{A}, \mathrm{mm}$

$x_{1 A}$ : the value of piston displacement at point $\mathrm{A}, \mathrm{mm}$

$\Delta_{Q L}$ : perturbation quantity of load flow at point A, $1 /$ $\min$

$\Delta_{p L}:$ perturbation quantity of working pressure at point $\mathrm{A}, \mathrm{MPa}$

$\Delta_{x v}$ : perturbation quantity of spool displacement at point $\mathrm{A}, \mathrm{mm}$

$\Delta_{x}$ : perturbation quantity of piston displacement at point $\mathrm{A}, \mathrm{mm}$

$K_{q}$ : flow gain

$K_{c}$ : flow-pressure coefficient, $\mathrm{m}^{3} \cdot \mathrm{s}^{-1} \cdot \mathrm{Pa}^{-1}$

$K_{c e}$ : total flow-pressure coefficient, $\mathrm{m}^{3} \cdot \mathrm{s}^{-1} \cdot \mathrm{Pa}^{-1}$

In order to achieve the adjustment of rolling pressure and working roll gap, hydraulic cylinder and 
electrohydraulic servo valve are primarily utilized to control the HAGC system. In consideration of function, an integrated HAGC system is formed by several automatic control systems. The following three closed loops are regarded to be the most important, control loop of rolling pressure, control loop of cylinder position, and control loop of thickness gauge monitoring, as displayed in Figure 2.

Rolling PCL is considered as the significant foundation for gauge control, which is used to control the pressure timely when the rolling conditions change so that the working roll gap can be well controlled. In the PCL system, pressure sensor is often used to measure the working chamber pressure of the cylinder to acquire real-time data. And the obtained pressure value will be transferred to the signal input end and used to make a comparison with the given pressure signal. If a deviation occurs, it will be adjusted by the pressure adjuster, and the power amplifier will be used to convert it into current signal and send it to electrohydraulic servo valve. When the current signal is gained by the servo valve, the flow into the working chamber of cylinder will be controlled via the motion of valve spool, and then the working chamber pressure of cylinder will be modulated until the feedback value is equivalent to the set value.

2.1. Controller. Currently, PID regulator is used as the controller, whose dynamic transfer function can be represented as

$$
G_{c}(s)=K_{p}\left(1+\frac{1}{T_{i} s}+T_{d} s\right)
$$

where $T_{d}$ and $T_{i}$ are the time constants of differential and integral, $K_{p}$ is the proportionality factor, and $s$ is Laplacian.

2.2. Servo Amplifier. For the purpose of flow regulation by controlling the servo valve, servo amplifier is used to transform voltage into electric current. The transfer function of servo amplifier is expressed as

$$
K_{a}=\frac{I}{U}
$$

where $K_{a}$ is the amplification coefficient $(\mathrm{A} / \mathrm{V}), U$ is the input voltage $(\mathrm{V})$, and $I$ is the output current $(\mathrm{A})$.

2.3. Hydraulic Power Unit. It can be primarily achieved by utilizing electrohydraulic servo valve to regulate the action of hydraulic cylinder, which is hydraulic power unit of the HAGC system. Its working principle is represented in Figure 3. With a view to the system, for purpose of improving the response performance, servo valve is utilized to regulate the rodless chamber of cylinder, and constant pressure oil is provided into the rod chamber of the cylinder.

2.3.1. Flow Equation of Servo Valve. By controlling the movement of valve spool with weak current signal, high power hydraulic energy can be controlled, which is the action of servo valve. Servo valve possesses the following special advantages, including high power amplification, small volume, quick response, and high dynamic property.

On the basis of the operating mechanism of servo valve, when spool displacement $x_{v}$ is taken as input and load flow $Q_{L}$ is used as output, the flow equation of servo valve can be gained:

$$
Q_{L}=f\left(x_{v}, p_{L}\right)= \begin{cases}C_{d} W x_{v} \sqrt{\frac{2\left(p_{s}-p_{L}\right)}{\rho},} & x_{v} \geq 0, \\ C_{d} W x_{v} \sqrt{\frac{2\left(p_{L}-p_{t}\right)}{\rho}}, & x_{v}<0,\end{cases}
$$

where $W$ is the area gradient of valve port $(\mathrm{m}), C_{d}$ is the flow factor of valve port, $p_{s}$ and $p_{t}$ are the supply and return pressure $(\mathrm{MPa}), p_{L}$ is the operating pressure of rodless chamber $(\mathrm{MPa})$, and $\rho$ is the density of hydraulic oil $\left(\mathrm{kg} / \mathrm{m}^{3}\right)$.

With respect to the connection between input current and spool displacement, it can be given by

$$
G_{v}(s)=\frac{x_{v}}{I_{c}}=\frac{K_{s v}}{\left(s^{2} / \omega_{s v}\right)+\left(2 \xi_{s v} / \omega_{s v}\right) s+1},
$$

where $I_{c}$ is the input current $(\mathrm{A}), K_{s v}$ is the amplification factor of spool displacement on input current (m/A), $\omega_{s v}$ is the specific angular frequency of servo valve $(\mathrm{rad} / \mathrm{s})$, and $\xi_{s v}$ is the damping factor of servo valve $(\mathrm{N} \cdot \mathrm{s} / \mathrm{m})$.

In regard to the characteristics of the servo valve, nonlinear saturation cannot be ignored, and the input current is restricted by

$$
I_{c}= \begin{cases}I, & I<I_{N} \\ I_{N}, & I \geq I_{N}\end{cases}
$$

where $I_{N}$ is the rated current of servo valve (A).

2.3.2. Flow Equation of Hydraulic Cylinder. The flow from servo valve into hydraulic cylinder satisfies the following requirements: firstly, it can drive the piston; then it can compensate for the leakage of cylinder; in addition, it can compensate for oil compression and chamber deformation.

On account of the rodless chamber of cylinder, the flow continuity equation can be represented by

$$
Q_{L}=A_{p} \dot{x}_{1}+C_{i p}\left(p_{L}-p_{b}\right)+C_{e p} p_{L}+\frac{V_{0}+A_{p} x_{1}}{\beta_{e}} \dot{p}_{L},
$$

where $x_{1}$ is the displacement of piston $\operatorname{rod}(\mathrm{mm}), A_{p}$ is the valid working area of piston $\left(\mathrm{m}^{2}\right), C_{e p}$ and $C_{i p}$ are the coefficients of external leakage and internal leakage $\left(\mathrm{m}^{3} \cdot \mathrm{s}^{-1} \cdot \mathrm{Pa}^{-1}\right), p_{b}$ is the operating pressure of rod chamber $(\mathrm{MPa}), \beta_{e}$ is the bulk modulus of oil (MPa) [54], and $V_{0}$ is the incipient volume of control chamber $\left(\mathrm{m}^{3}\right)$.

In consideration of the tiny change of piston displacement when system works stably, that is, $A_{p} x_{1} \ll V_{0}$, then it can be concluded that the cumulative volume of control chamber is approximately equivalent to incipient volume. Additionally, in view of the actual system, it can be ignored for this reason that the external leakage is small. Hence, with 


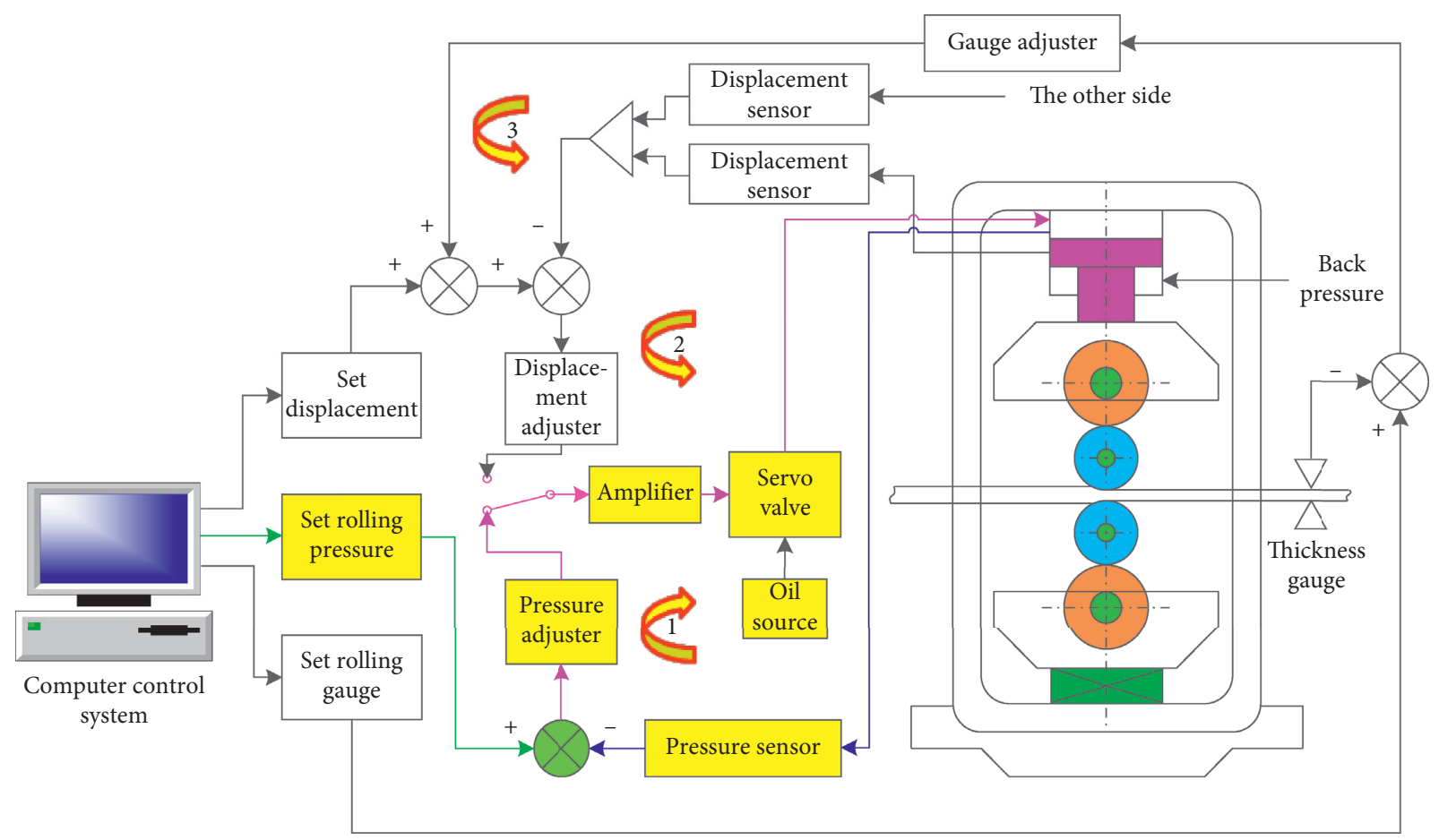

FIGURE 2: Function schematic of HAGC system.

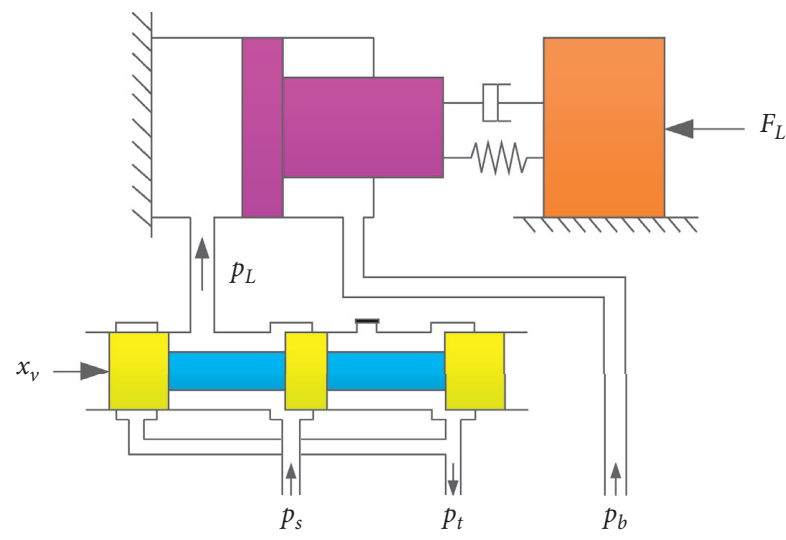

Figure 3: Principle of hydraulic cylinder controlled by servo valve.

regard to the flow continuous equation of the control chamber of cylinder, it can be further expressed as

$$
Q_{L}=A_{p} \dot{x}_{1}+C_{i p}\left(p_{L}-p_{b}\right)+\frac{V_{0}}{\beta_{e}} \dot{p}_{L}
$$

2.4. Load. The load of HAGC system is composed of multiple sets of rolls which possess symmetric structures. Four-high mill is commonly used in the load roll system, whose basic structure is shown in Figure 4.

In current times, for the purpose of the convenient study, the load rolls is primarily classified as the following two models: one is single DOF model according to the lumped model, and the other is multi-DOF mass distribution model according to the distribution parameter model.
Furthermore, it has been demonstrated by enormous researches that the stiffness is asymmetrical in view of the URS and LRS of rolling mill. In accordance with the two-DOF mass distribution load model, the corresponding analysis for the HAGC system is more aligned with that in the actual operation conditions $[55,56]$.

To get closer to the authentic operating conditions, the URS and LRS are utilized as two different mass systems, respectively. Then the two-DOF mechanical model of load roll system is instituted, as represented in Figure 5.

On the basis of Newton's second law, the force balance equation of load of the HAGC system can be given by

$$
\begin{aligned}
p_{L} A_{p}-p_{b} A_{b} & =m_{1} \dot{x}_{1}+c_{1} \dot{x}_{1}+k_{1} x_{1}+F_{L}, \\
F_{L} & =m_{2} \ddot{x}_{2}+c_{2} \dot{x}_{2}+k_{2} x_{2},
\end{aligned}
$$

where $m_{1}$ and $m_{2}$ are the equivalent mass of moving elements of URS and LRS (kg); $x_{1}$ and $x_{2}$ are the displacement of URS and LRS (mm); $c_{1}$ and $c_{2}$ are the linear damping coefficient of moving elements of URS and LRS (N.s/m); $k_{1}$ is the linear stiffness coefficient between upper frame beam and moving elements of URS $(\mathrm{N} / \mathrm{m}) ; k_{2}$ is the linear stiffness coefficient between lower frame beam and moving elements of LRS $(\mathrm{N} / \mathrm{m}) ; A_{b}$ is the effective operating area of piston of rod chamber $\left(\mathrm{m}^{2}\right) ; F_{L}$ is the load force acting on roll system $(\mathrm{N})$.

2.5. Sensor. The pressure sensor is considered to be the primary feedback element of the PCL system. In view of the transfer function of pressure sensor, it is expressed as 

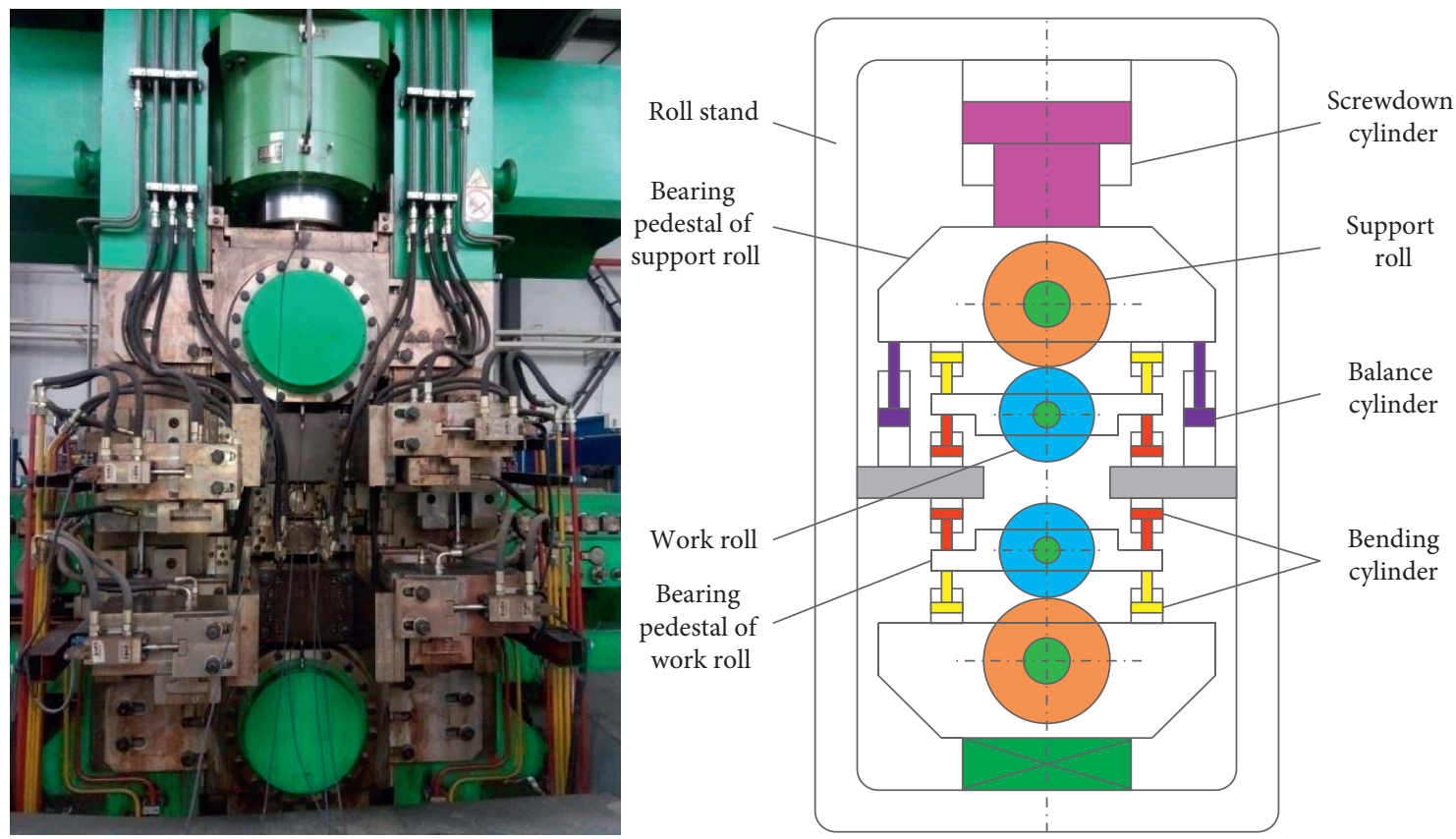

FIgURE 4: Schematic of load roll of four-high mill.

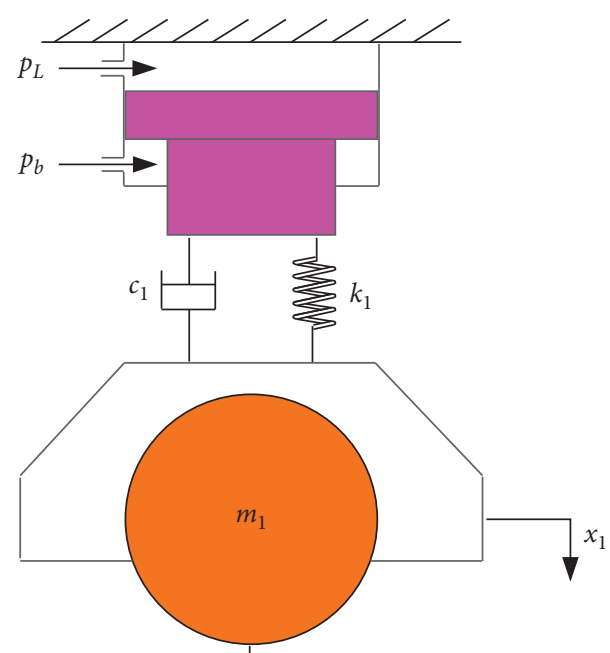

where $K_{f}$ is the amplification coefficient $(\mathrm{V} / \mathrm{Pa})$ and $T_{f}$ is the time constant of pressure sensor.

\section{Incremental Transfer Model of the PCL System}

3.1. Hydraulic Transmission Element. On the basis of the above mathematical model and information transfer relationship, when the system is in equilibrium at the working point $\mathrm{A}$, the balance equations of hydraulic transmission part of the HAGC system can be deduced by

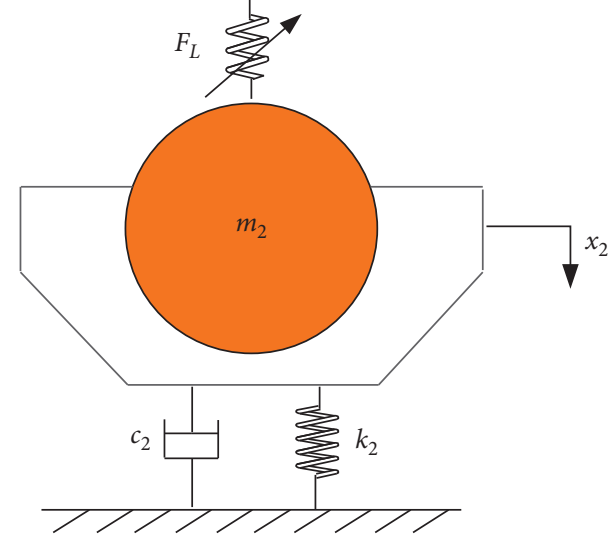

FIgUre 5: Two-DOF mechanics model.

$$
G_{p}(s)=\frac{K_{f}}{T_{f} s+1},
$$

$$
\begin{aligned}
& Q_{L A}=f\left(x_{v A}, p_{L A}\right), \\
& Q_{L A}=A_{p} \dot{x}_{1 A}+C_{i p}\left(p_{L A}-p_{b}\right)+\frac{V_{0}}{\beta_{e}} \dot{p}_{L A},
\end{aligned}
$$

$p_{L A} A_{p}-p_{b} A_{b}=m_{1} \ddot{x}_{1 A}+c_{1} \dot{x}_{1 A}+k_{1} x_{1 A}+F_{L A}$,

where $Q_{L A}$ is the value of $Q_{L}$ at the working point $A ; p_{L A}$ is the value of $p_{L}$ at point $\mathrm{A} ; x_{v A}$ is the value of $x_{v}$ at point $\mathrm{A}$; and $x_{1 A}$ is the value of $x_{1}$ at point A.

When small perturbation occurs in system close to the operating point $\mathrm{A}$, all the variables of system will change around the equilibrium point; there are

$$
\begin{aligned}
Q_{L} & =Q_{L A}+\Delta Q_{L}, \\
x_{v} & =x_{v A}+\Delta x_{v}, \\
p_{L} & =p_{L A}+\Delta p_{L}, \\
x_{1} & =x_{1 A}+\Delta x,
\end{aligned}
$$


where $\Delta Q_{L}$ and $\Delta p_{L}$ are the perturbation quantity of $Q_{L}$ and $p_{L}$ at point $\mathrm{A} ; \Delta x_{v}$ and $\Delta x$ are the perturbation quantity of $x_{v}$ and $x_{1}$ at point $\mathrm{A}$.

By the use of the Taylor series, the load flow of servo valve is unfolded close to the operating point A. Furthermore, the high-order minor terms are eliminated; there is

$$
Q_{L}=Q_{L A}+\left.\frac{\partial Q_{L}}{\partial x_{v}}\right|_{A} \Delta x_{v}+\left.\frac{\partial Q_{L}}{\partial p_{L}}\right|_{A} \Delta p_{L}
$$

Then, when a small disturbance motion appears in the system near the operating point $A$, the approximate equation of perturbation flow can be deduced.

$$
\begin{aligned}
\Delta Q_{L} & =Q_{L}-Q_{L A}=\left.\frac{\partial Q_{L}}{\partial x_{v}}\right|_{A} \Delta x_{v}+\left.\frac{\partial Q_{L}}{\partial p_{L}}\right|_{A} \Delta p_{L} \\
& =K_{q} \Delta x_{v}-K_{c} \Delta p_{L}
\end{aligned}
$$

where $K_{q}$ is the flow gain, $K_{q}=\left(\partial Q_{L} / \partial x_{v}\right)$, and $K_{c}$ is the flow-pressure coefficient, $K_{c}=-\left(\partial Q_{L} / \partial p_{L}\right)$.

When small disturbance motion happens in the system close to the operating point $\mathrm{A}$, the flow continuity equation of cylinder can be represented as

$$
\begin{aligned}
Q_{L A}+\Delta Q_{L}= & A_{p}\left(\dot{x}_{1 A}+\Delta \dot{x}\right)+C_{i p}\left[\left(p_{L A}+\Delta p_{L}\right)-p_{b}\right] \\
& +\frac{V_{0}}{\beta_{e}}\left(\dot{p}_{L A}+\Delta \dot{p}_{L}\right) .
\end{aligned}
$$

Combined with equation (16) and equation (11), there is

$$
\Delta Q_{L}=A_{p} \Delta \dot{x}+C_{i p} \Delta p_{L}+\frac{V_{0}}{\beta_{e}} \Delta \dot{p}_{L}
$$

When small disturbance motion occurs in the system close to the operating point $\mathrm{A}$, the load force equilibrium equation can be given by

$$
\begin{aligned}
& \left(p_{L A}+\Delta p_{L}\right) A_{p}-p_{b} A_{b} \\
& =m_{1}\left(\ddot{x}_{1 A}+\Delta \ddot{x}\right)+c_{1}\left(\dot{x}_{1 A}+\Delta \dot{x}\right)+k_{1}\left(x_{1 A}+\Delta x\right)+F_{L A} .
\end{aligned}
$$

In combination with equation (18) and equation (12), there is

$$
\Delta p_{L} A_{p}=m_{1} \Delta \ddot{x}+c_{1} \Delta \dot{x}+k_{1} \Delta x .
$$

In combination with equations (15), (17), and (19), when small disturbance motion happens in the system close to the operating point $\mathrm{A}$, the incremental equations of the hydraulic transmission element can be derived.

$$
\left\{\begin{array}{l}
\Delta Q_{L}=K_{q} \Delta x_{v}-K_{c} \Delta p_{L}, \\
\Delta Q_{L}=A_{p} \Delta \dot{x}+C_{i p} \Delta p_{L}+\frac{V_{0}}{\beta_{e}} \Delta \dot{p}_{L} \\
\Delta p_{L}=\frac{m_{1} \Delta \ddot{x}+c_{1} \Delta \dot{x}+k_{1} \Delta x}{A_{p}}
\end{array} .\right.
$$

Laplace transformation is performed on equation (20); the following equations are obtained:

$$
\left\{\begin{array}{l}
\Delta Q_{L}=K_{q} \Delta x_{v}-K_{c} \Delta p_{L} \\
\Delta Q_{L}=A_{p} s \Delta x+\left(C_{i p}+\frac{V_{0}}{\beta_{e}} s\right) \Delta p_{L} \\
\Delta p_{L}=\frac{\left(m_{1} s^{2}+c_{1} s+k_{1}\right) \Delta x}{A_{p}}
\end{array}\right.
$$

Through the further organization of equation (21), as for the connection between $\Delta p_{L}$ and $\Delta x_{v}$, it can be deduced that

$$
\Delta p_{L}=\frac{1}{s\left(\left(A_{p}^{2} /\left(m_{1} s^{2}+c_{1} s+k_{1}\right)\right)+\left(V_{0} / \beta_{e}\right)\right)+K_{c e}} K_{q} \Delta x_{v},
$$

where $K_{c e}$ is the total flow-pressure coefficient $\left(\mathrm{m}^{3} \cdot \mathrm{s}^{-1} \cdot \mathrm{Pa}^{-1}\right), K_{c e}=C_{i p}+K_{c}$.

Assume that

$$
G_{2}(s)=\frac{1}{s\left(\left(A_{p}^{2} /\left(m_{1} s^{2}+c_{1} s+k_{1}\right)\right)+\left(V_{0} / \beta_{e}\right)\right)+K_{c e}} .
$$

Additionally, in accordance with the aforementioned theoretical formula (3), there is

$$
K_{q}=\frac{\partial Q_{L}}{\partial x_{v}}= \begin{cases}C_{d} W \sqrt{\frac{2\left(p_{s}-p_{L}\right)}{\rho}}, & x_{v} \geq 0, \\ C_{d} W \sqrt{\frac{2\left(p_{L}-p_{t}\right)}{\rho}}, & x_{v}<0 .\end{cases}
$$

From equations (22)-(24), the information transfer connection between $\Delta p_{L}$ and $\Delta x_{v}$ can be acquired, which is linked by the transfer function $G_{2}(s)$ and nonlinear mathematical formula $K_{q}$.

3.2. Feedback and Control Element. When PCL is adopted in the HAGC system, on the basis of the mathematical model of pressure feedback and control, the connection between $\Delta x_{v}$ and $\Delta p_{L}$ can be derived. 


$$
\begin{aligned}
\Delta x_{v} & =G_{c}(s) K_{a} G_{v}(s) G_{p}(s) \Delta p_{L} \\
& =\frac{K_{p}\left(1+\left(1 / T_{i} s\right)+T_{d} s\right) K_{a} K_{f} K_{s v}}{\left(T_{f} s+1\right)\left(\left(s^{2} / \omega_{s v}\right)+\left(2 \xi_{s v} / \omega_{s v}\right) s+1\right)} \Delta p_{L} .
\end{aligned}
$$

Suppose that

$$
G_{4}(s)=\frac{K_{p}\left(1+\left(1 / T_{i} s\right)+T_{d} s\right) K_{a} K_{f} K_{s v}}{\left(T_{f} s+1\right)\left(\left(s^{2} / \omega_{s v}\right)+\left(2 \xi_{s v} / \omega_{s v}\right) s+1\right)} .
$$

From formulas (25) and (26), the information connection between $\Delta x_{v}$ and $\Delta p_{L}$ is linked by the transfer function $G_{4}(s)$. Additionally, in accordance with the limitation condition of input current described in equation (5), it can be seen that $G_{4}(s)$ presents a nonlinear saturation feature and is considered to be a nonlinear transfer function.

\section{Frequency Criterion for Absolute Stability of the Nonlinear Closed-Loop System}

According to modern control theory and nonlinear vibration theory, if the nonlinear closed-loop system is subjected to arbitrary large initial disturbance, all the state point of the system can return to the equilibrium point; then the balance point of the system is global asymptotic stability or absolute stability $[57,58]$.

The transfer block diagram of the nonlinear closed-loop feedback system is revealed in Figure 6 . The transfer function $G(s)$ of open loop is often a rational fraction. According to its pole distribution, the nonlinear closed-loop control system can be classified into two categories:

(1) Formal system: all poles of $G(s)$ have negative real parts, which is equivalent to the asymptotic stability of the open-loop system.

(2) Critical system: at least one pole of the transfer function $G(s)$ is on the imaginary axis, and the other poles have negative real parts, which is the critical stability of the open-loop system.

Popov's theorem: if the nonlinear feature function $f[e(t)]$ of the nonlinear closed-loop feedback system can satisfy one of the following two conditions, then the balance point of the system is global asymptotic stability or absolute stability.

Condition 1. For formal system, it must be satisfied as

$$
f(0)=0, \quad 0 \leq \frac{f[e(t)]}{e(t)} \leq P .
$$

Condition 2. For critical system, it must be satisfied as

$$
f(0)=0, \quad 0<\varepsilon \leq \frac{f[e(t)]}{e(t)} \leq P .
$$

And, for all $\omega \geq 0$ and any small parameters $\varepsilon>0$, any finite constants $\eta$ can make the following inequalities true:

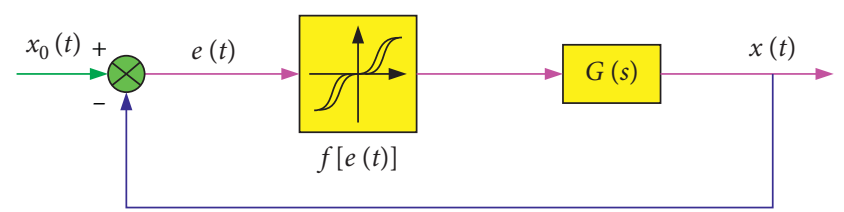

Figure 6: Transfer block diagram of nonlinear closed-loop feedback system.

$$
\operatorname{Re}[(1+i \eta \omega) G(i \omega)]+\frac{1}{P}>0
$$

Based on the above theorem, Popov deduced the geometric criterion to estimate the absolute stability of nonlinear closed-loop system. For practical application, the derivation process of this method is described as follows [59].

First, the open-loop frequency characteristic $G(i \omega)$ is decomposed into forms that contain real and imaginary parts:

$$
G(i \omega)=\operatorname{Re}(\omega)+i \operatorname{Im}(\omega)
$$

Equation (30) is substituted into equation (29); then the real domain inequality which guarantees the absolute stability of the system is derived:

$$
\operatorname{Re}(\omega)-\eta \omega \operatorname{Im}(\omega)+\frac{1}{P}>0 .
$$

Secondly, the formula of the modified frequency feature $G^{*}(i \omega)$ is defined as

$$
\begin{aligned}
G^{*}(i \omega) & =X(\omega)+i Y(\omega), \\
X(\omega) & =\operatorname{Re}(\omega) \\
Y(\omega) & =\omega \operatorname{Im}(\omega)
\end{aligned}
$$

Then, the characteristic curve of $G^{*}(i \omega)$ can be drawn on a complex plane according to equation (32).

By substituting equation (33) into equation (31), the absolute stability condition of nonlinear closed-loop system can be expressed as

$$
X(\omega)-\eta Y(\omega)+\frac{1}{P}>0 .
$$

If the inequality sign in equation (34) is changed into an equal sign, then the linear equation on the plane $G^{*}(i \omega)$ is

$$
X(\omega)-\eta Y(\omega)+\frac{1}{P}=0 .
$$

The $G^{*}(i \omega)$ plane is established with $X(\omega)$ as the horizontal axis and $Y(\omega)$ as the vertical axis. When the point $Q$ of $X(\omega)=-P^{-1}$ is taken on the real axis, then the line $l$ which passes through the point $Q\left(-P^{-1}, 0\right)$ with slope $(1 / \eta)$ and is satisfied with equation (35) is called the Popov line. The $G^{*}(i \omega)$ plane is divided into two areas by Popov line: stable region and unstable region, as shown in Figure 7. Because the slope $(1 / \eta)$ of line $l$ can take any finite value, so the characteristic curve of $G^{*}(i \omega)$ is firstly analyzed. Furthermore, the appropriate value of $P$ is determined 


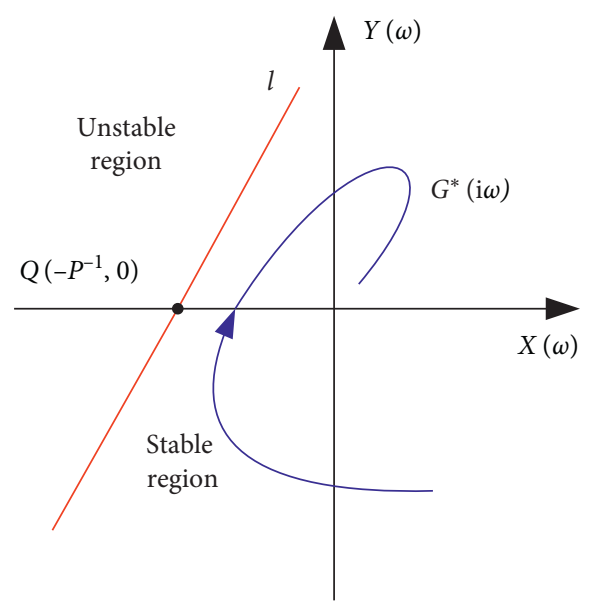

Figure 7: Relationship between Popov line $l$ and frequency characteristic curve.

according to the nonlinear characteristic curve $f[e(t)]$ by equations (27) or (28). Usually, the value of $P$ needs to be taken as small as possible. Finally, the Popov line $l$ is drawn through the point $Q\left(-P^{-1}, 0\right)$ so that the characteristic curve $G^{*}(i \omega)$ is located in right stable region of line $l$. Then the nonlinear system is absolute stability.

The above description of the Popov frequency criterion is further explained by using a set of legends below. The corrected frequency characteristic curves $G_{1}^{*}(\mathrm{i} \omega), G_{2}^{*}(i \omega)$, and $G_{3}^{*}(i \omega)$ of three different nonlinear closed-loop systems are plotted in Figure 8. Firstly, $P_{1}, P_{2}$, and $P_{3}$ are determined according to the nonlinear characteristic curves $f_{1}[e(t)]$, $f_{2}[e(t)]$, and $f_{3}[e(t)]$. Then, the positions of $Q_{1}\left(-P_{1}^{-1}, 0\right)$, $Q_{2}\left(-P_{2}^{-1}, 0\right)$, and $Q_{3}\left(-P_{3}^{-1}, 0\right)$ are determined. Furthermore, according to Popov's theorem, the stability of these three kinds of nonlinear systems can be evaluated.

As displayed in Figure 8(a), the intersection of $G_{1}^{*}(i \omega)$ and real axis $X(\omega)$ is on the right side of $Q_{1}\left(-P_{1}^{-1}, 0\right)$. And the characteristic curve $G_{1}^{*}(i \omega)$ is also on the right side of $Q_{1}$. Through the point $Q_{1}$, it is easy to plot a line $l$ so that the characteristic curve $G_{1}^{*}(i \omega)$ is located in the right stable region. Hence, the system is absolutely stable.

As shown in Figure 8(b), the intersection of $G_{2}^{*}(i \omega)$ and real axis $X(\omega)$ is at the right side of $Q_{2}\left(-P_{2}^{-1}, 0\right)$. However, over the point $Q_{2}$, we cannot draw a line $l$ that makes the characteristic curve $G_{2}^{*}(i \omega)$ be completely located in the right stable region. So the system is unstable.

As demonstrated in Figure 8(c), the intersection of $G_{3}^{*}(i \omega)$ and real axis $X(\omega)$ is at the left side of $Q_{3}\left(-P_{3}^{-1}, 0\right)$. Therefore, through the point $Q_{3}$, the line $l$ cannot be obtained so that the characteristic curve $G_{3}^{*}(i \omega)$ is completely in the right stable region. So the system is also unstable.

In summary, according to the Popov frequency criterion, the stabilization of nonlinear closed-loop system can be easily discriminated.

\section{Instability Condition of the PCL System}

In accordance with the above deduced transitive relation, the transfer block diagram is established about the perturbation of the PCL system, as displayed in Figure 9. The mathematical model is used to research the absolute stability of system via the frequency method.

In the work, in order to estimate the absolute stability of the PCL of the HAGC system, the Popov frequency criterion is employed. For this, in transfer function $G_{2}(s)$, assume that $s=i \omega$; then the frequency characteristic is expressed as

$$
G_{2}(i \omega)=\operatorname{Re}_{2}(\omega)+i \operatorname{Im}_{2}(\omega) .
$$

Substitute the expression (23) of $G_{2}(s)$ into equation (36); then the features of real frequency and imaginary frequency can be represented as

$$
\begin{aligned}
\operatorname{Re}_{2}(\omega)= & {\left[K_{c e}+\frac{A_{p}^{2} \omega^{2} c_{1}}{\left(k_{1}-m_{1} \omega^{2}\right)^{2}+c_{1}^{2} \omega^{2}}\right] } \\
& \times\left\{\left[K_{c e}+\frac{A_{p}^{2} \omega^{2} c_{1}}{\left(k_{1}-m_{1} \omega^{2}\right)^{2}+c_{1}^{2} \omega^{2}}\right]^{2}+\left[\frac{V_{0} \omega}{\beta_{e}}+\frac{A_{p}^{2} \omega\left(k_{1}-m_{1} \omega^{2}\right)}{\left(k_{1}-m_{1} \omega^{2}\right)^{2}+c_{1}^{2} \omega^{2}}\right]^{2}\right\}^{-1}, \\
\operatorname{Im}_{2}(\omega)= & {\left[-\frac{V_{0} \omega}{\beta_{e}}-\frac{A_{p}^{2} \omega\left(k_{1}-m_{1} \omega^{2}\right)}{\left(k_{1}-m_{1} \omega^{2}\right)^{2}+c_{1}^{2} \omega^{2}}\right] } \\
& \times\left\{\left[K_{c e}+\frac{A_{p}^{2} \omega^{2} c_{1}}{\left(k_{1}-m_{1} \omega^{2}\right)^{2}+c_{1}^{2} \omega^{2}}\right]^{2}+\left[\frac{V_{0} \omega}{\beta_{e}}+\frac{A_{p}^{2} \omega\left(k_{1}-m_{1} \omega^{2}\right)}{\left(k_{1}-m_{1} \omega^{2}\right)^{2}+c_{1}^{2} \omega^{2}}\right]^{2}\right\}^{-1} .
\end{aligned}
$$

The following definition is obtained about the expression of corrected frequency characteristic $G_{2}^{*}(i \omega)$ : 


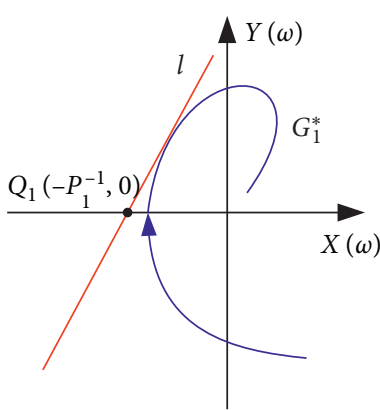

(a)

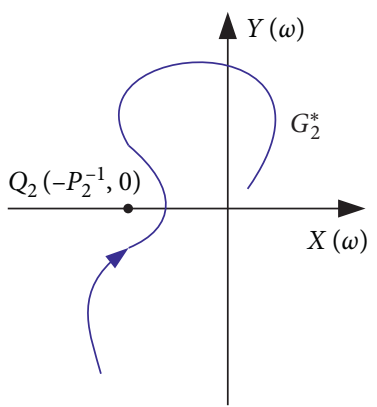

(b)

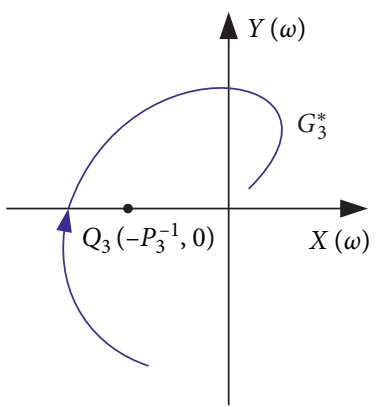

(c)

Figure 8: Modified frequency characteristic curves of various systems. (a) Absolute stability system. (b) Unstable system. (c) Unstable system.

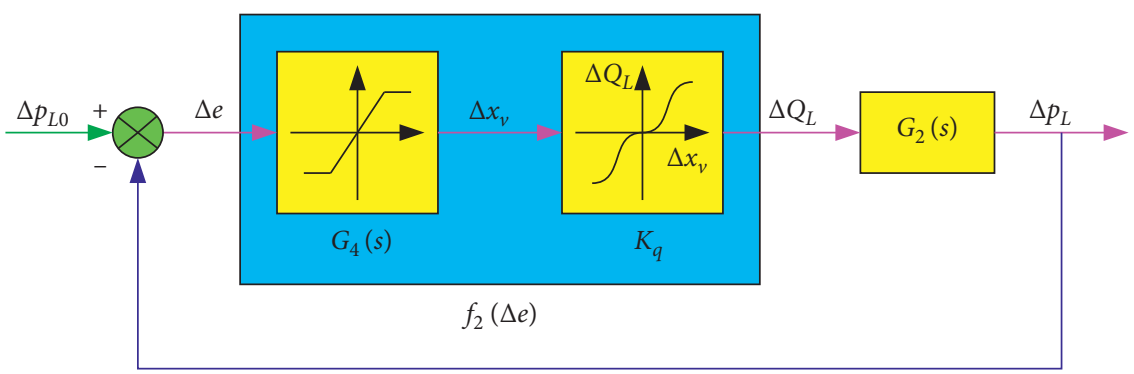

FIGURE 9: Transfer block diagram of the perturbation of PCL system.

$$
\begin{aligned}
G_{2}^{*}(i \omega) & =X_{2}(\omega)+i Y_{2}(\omega) \\
X_{2}(\omega) & =\operatorname{Re}_{2}(\omega) \\
Y_{2}(\omega) & =\omega \operatorname{Im}_{2}(\omega)
\end{aligned}
$$

Then, on the basis of equations (37), (38), and (40), the modified features of real frequency and imaginary frequency can be expressed as

$$
\begin{aligned}
X_{2}(\omega)= & {\left[K_{c e}+\frac{A_{p}^{2} \omega^{2} c_{1}}{\left(k_{1}-m_{1} \omega^{2}\right)^{2}+c_{1}^{2} \omega^{2}}\right] } \\
& \times\left\{\left[K_{c e}+\frac{A_{p}^{2} \omega^{2} c_{1}}{\left(k_{1}-m_{1} \omega^{2}\right)^{2}+c_{1}^{2} \omega^{2}}\right]^{2}+\left[\frac{V_{0} \omega}{\beta_{e}}+\frac{A_{p}^{2} \omega\left(k_{1}-m_{1} \omega^{2}\right)}{\left(k_{1}-m_{1} \omega^{2}\right)^{2}+c_{1}^{2} \omega^{2}}\right]^{2},\right. \\
Y_{2}(\omega)= & -\omega^{2}\left[\frac{V_{0}}{\beta_{e}}+\frac{A_{p}^{2}\left(k_{1}-m_{1} \omega^{2}\right)}{\left(k_{1}-m_{1} \omega^{2}\right)^{2}+c_{1}^{2} \omega^{2}}\right] \\
& \times\left\{\left[K_{c e}+\frac{A_{p}^{2} \omega^{2} c_{1}}{\left(k_{1}-m_{1} \omega^{2}\right)^{2}+c_{1}^{2} \omega^{2}}\right]^{2}+\left[\frac{V_{0} \omega}{\beta_{e}}+\frac{A_{p}^{2} \omega\left(k_{1}-m_{1} \omega^{2}\right)}{\left(k_{1}-m_{1} \omega^{2}\right)^{2}+c_{1}^{2} \omega^{2}}\right]^{2}\right\}^{-1} .
\end{aligned}
$$

The intersection between $G_{2}^{*}(i \omega)$ and the real axis is considered to be the critical point of the Popov criterion. The coordinate is defined as $\left(-P_{2}^{-1}, 0\right)$. By using equations (41) and (42), the abscissa value of the critical point can be acquired: 


$$
X_{2}\left(\omega^{*}\right)=\frac{m_{1} \beta_{e}\left[m_{1} \beta_{e} A_{p}^{2}-V_{0} c_{1}^{2}+\sqrt{\left(V_{0} c_{1}^{2}-m_{1} \beta_{e} A_{p}^{2}\right)^{2}-4 m_{1} k_{1} V_{0}^{2} c_{1}^{2}}\right]}{\left(K_{c e} m_{1} \beta_{e}+V_{0} c_{1}\right)\left[m_{1} \beta_{e} A_{p}^{2}-V_{0} c_{1}^{2}+\sqrt{\left(V_{0} c_{1}^{2}-m_{1} \beta_{e} A_{p}^{2}\right)^{2}-4 m_{1} k_{1} V_{0}^{2} c_{1}^{2}}\right]+2 c_{1} m_{1} k_{1} V_{0}^{2}} .
$$

Then through the definition of the Popov line, it can be found that

$$
\begin{aligned}
P_{2} & =-\frac{1}{X_{2}\left(\omega^{*}\right)} \\
& =\frac{\left(K_{c e} m_{1} \beta_{e}+V_{0} c_{1}\right)\left[m_{1} \beta_{e} A_{p}^{2}-V_{0} c_{1}^{2}+\sqrt{\left(V_{0} c_{1}^{2}-m_{1} \beta_{e} A_{p}^{2}\right)^{2}-4 m_{1} k_{1} V_{0}^{2} c_{1}^{2}}\right]+2 c_{1} m_{1} k_{1} V_{0}^{2}}{m_{1} \beta_{e}\left[m_{1} \beta_{e} A_{p}^{2}-V_{0} c_{1}^{2}+\sqrt{\left.\left(V_{0} c_{1}^{2}-m_{1} \beta_{e} A_{p}^{2}\right)^{2}-4 m_{1} k_{1} V_{0}^{2} c_{1}^{2}\right]}\right.} \\
= & \frac{2 c_{1} k_{1} V_{0}^{2}}{\beta_{e}\left[V_{0} c_{1}^{2}-m_{1} \beta_{e} A_{p}^{2}-\sqrt{\left(V_{0} c_{1}^{2}-m_{1} \beta_{e} A_{p}^{2}\right)^{2}-4 m_{1} k_{1} V_{0}^{2} c_{1}^{2}}\right]}-\frac{c_{1} V_{0}}{m_{1} \beta_{e}}-K_{c e} \cdot
\end{aligned}
$$

In accordance with Popov's theorem, if equation (27) or (28) is satisfied by the nonlinear characteristic function $f_{2}(\Delta e)=G_{4}(s) K_{q} \Delta e$ of the PCL system, the balance point of the system is absolute stability; that is,

$$
f(0)=0, \quad 0<\frac{f_{2}(\Delta e)}{\Delta e} \leq P_{2} .
$$

From equation (45), it can be found that if the feature curve of nonlinear transfer function $G_{4}(s) K_{q}$ is situated in the sector area, the PCL system is global asymptotic stability.
The sector area consists of the horizontal axis and the line $l_{2}$ which traverse the area with a slope $P_{2}$, as displayed in Figure 10(a). On the contrary, if the characteristic curve of $G_{4}(s) K_{q}$ is beyond the sector area (Figure 10(b)), it can be determined that the PCL system is unstable. At this time, as the system parameters change, intricate dynamic behavior potentially happens.

Based on the above analysis, as for the absolute stability conditions of the PCL system, they can be deduced:

$$
G_{4}(s) K_{q} \leq \frac{2 c_{1} k_{1} V_{0}^{2}}{\beta_{e}\left[V_{0} c_{1}^{2}-m_{1} \beta_{e} A_{p}^{2}-\sqrt{\left(V_{0} c_{1}^{2}-m_{1} \beta_{e} A_{p}^{2}\right)^{2}-4 m_{1} k_{1} V_{0}^{2} c_{1}^{2}}\right]}-\frac{c_{1} V_{0}}{m_{1} \beta_{e}}-K_{c e} .
$$

Then, in terms of the instability conditions of the PCL system, it can be further obtained:

$$
\frac{2 c_{1} k_{1} V_{0}^{2}}{\beta_{e}\left[V_{0} c_{1}^{2}-m_{1} \beta_{e} A_{p}^{2}-\sqrt{\left(V_{0} c_{1}^{2}-m_{1} \beta_{e} A_{p}^{2}\right)^{2}-4 m_{1} k_{1} V_{0}^{2} c_{1}^{2}}\right]}-\frac{c_{1} V_{0}}{m_{1} \beta_{e}}-K_{c e}<G_{4}(s) K_{q} .
$$

Substitute the formula of $G_{4}(s)$ and $K_{q}$ into equation (47); when the spool displacement is positive $\left(x_{v} \geq 0\right)$, then the instability condition of the PCL system can be expressed 


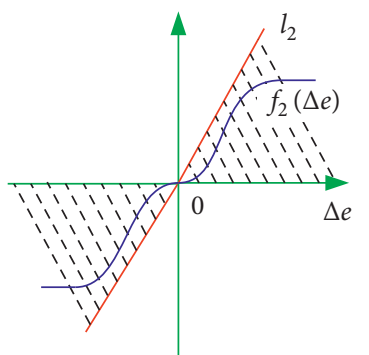

(a)

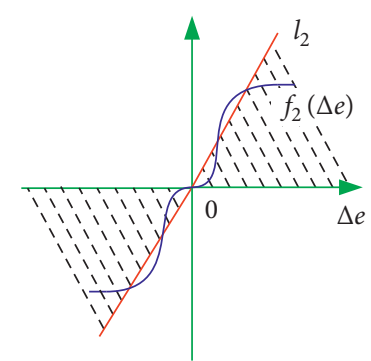

(b)

Figure 10: Relationship between $l_{2}$ and the nonlinear feature curve of PCL system. (a) Absolute stability system. (b) Unstable system.

$$
\begin{aligned}
& \frac{2 c_{1} k_{1} V_{0}^{2}}{\beta_{e}\left[V_{0} c_{1}^{2}-m_{1} \beta_{e} A_{p}^{2}-\sqrt{\left(V_{0} c_{1}^{2}-m_{1} \beta_{e} A_{p}^{2}\right)^{2}-4 m_{1} k_{1} V_{0}^{2} c_{1}^{2}}\right]}-\frac{c_{1} V_{0}}{m_{1} \beta_{e}}-K_{c e} \\
& <\frac{K_{p}\left(1+\left(1 / T_{i} s\right)+T_{d} s\right) K_{a} K_{f} K_{s v}}{\left(T_{f} s+1\right)\left(\left(s^{2} / \omega_{s v}\right)+\left(2 \xi_{s v} / \omega_{s v}\right) s+1\right)} C_{d} W \sqrt{\frac{2\left(p_{s}-p_{L}\right)}{\rho}}
\end{aligned}
$$

As the spool displacement is negative $\left(x_{v}<0\right)$, with regard to the instability condition of the PCL system, it can be represented as

$$
\begin{aligned}
& \frac{2 c_{1} k_{1} V_{0}^{2}}{\beta_{e}\left[V_{0} c_{1}^{2}-m_{1} \beta_{e} A_{p}^{2}-\sqrt{\left(V_{0} c_{1}^{2}-m_{1} \beta_{e} A_{p}^{2}\right)^{2}-4 m_{1} k_{1} V_{0}^{2} c_{1}^{2}}\right]}-\frac{c_{1} V_{0}}{m_{1} \beta_{e}}-K_{c e} \\
& <\frac{K_{p}\left(1+\left(1 / T_{i} s\right)+T_{d} s\right) K_{a} K_{f} K_{s v}}{\left(T_{f} s+1\right)\left(\left(s^{2} / \omega_{s v}\right)+\left(2 \xi_{s v} / \omega_{s v}\right) s+1\right)} C_{d} W \sqrt{\frac{2\left(p_{L}-p_{t}\right)}{\rho}}
\end{aligned}
$$

\section{Experiment Research}

6.1. Test System. The 650 4/6-roll cold rolling mill from the "National Engineering Research Center for Equipment and Technology of Cold Strip Rolling" is employed as a test object. Some physical photos of the test system are displayed in Figure 11. The test mill can provide good experimental conditions for this study, including complete basic automation, process automation, HAGC, and other control systems.

The acquisition system of vibration data in the test is mainly composed of PCB vibration acceleration sensors and NI data acquisition equipment. Due to the working principle of load rollers and the installation layout, the vibration acceleration sensors are installed on the bearing seat of each work roller. The vibration responses of the load of the HAGC system are measured by the sensors and collected by the data acquisition system.

6.2. Setting of Steady State. The oil supply pressure is set to $18 \mathrm{MPa}$, and the back pressure is set to $1 \mathrm{MPa}$. The system is switched to PCL control, and the unilateral rolling force is set to $350 \mathrm{kN}$. Then, a square wave signal (amplitude $50 \mathrm{kN}$; frequency $0.1 \mathrm{~Hz}$ ) and a sine signal (amplitude $20 \mathrm{kN}$; frequency $0.1 \mathrm{~Hz}$ ) are input, respectively. Meanwhile, the parameters of the PID controller are adjusted to achieve the best state of the dynamic performance of the HAGC system as far as possible. The final set of parameters are $K_{p}=0.1$, $T_{i}=4000 \mathrm{~ms}$, and $T_{d}=0$. The following effect of rolling force when the square wave signal is input is shown in Figure 12, and the following effect of rolling force when the sine signal is input is displayed in Figure 13. It can be seen that the rolling force can follow the typical signal input well. This indicates that the system possesses good dynamic performance under this controller parameters combination and can be used as the initial steady state of the tests.

6.3. Collection of Test Data. With regard to the derived instability condition expressions (48) and (49), the parameters that often change in the practical working process are the proportional factor $K_{p}$ of controller and the operating pressure $p_{L}$ of rodless chamber. Hence, in the following 


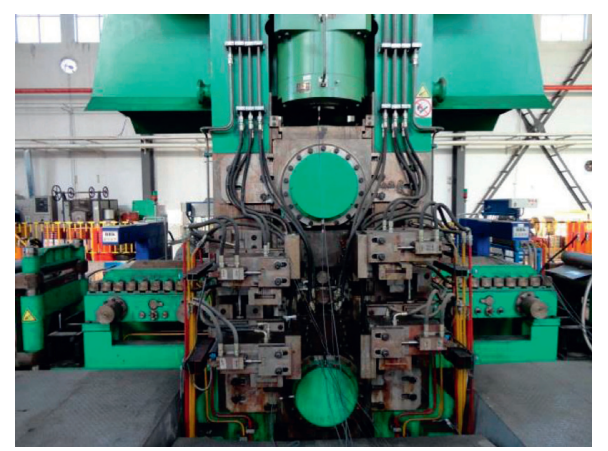

(a)

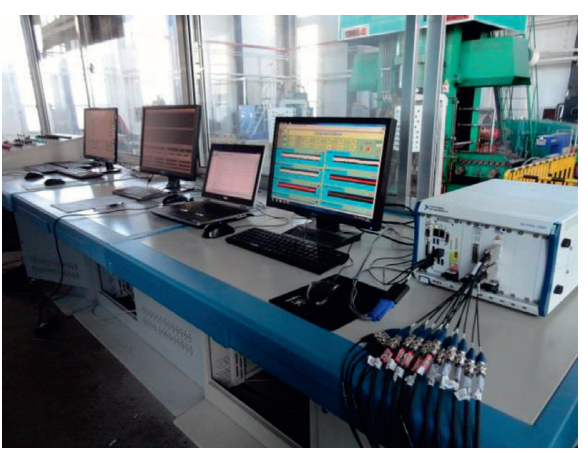

(b)

Figure 11: Photos of test system. (a) Test platform. (b) Computer control and data acquisition system.

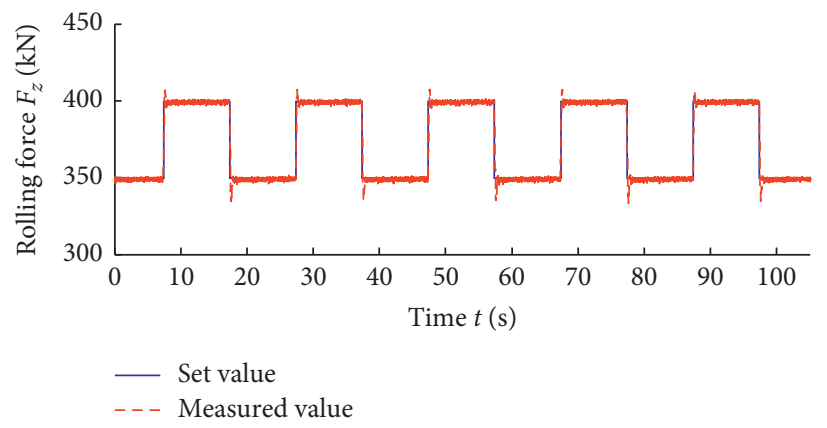

(a)

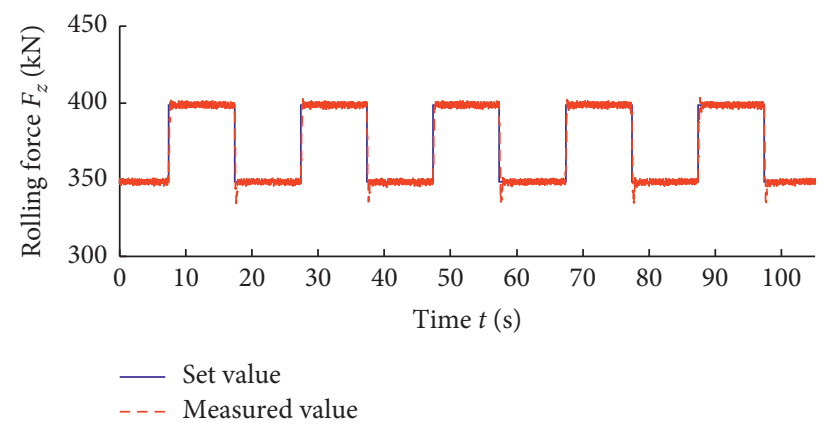

(b)

Figure 12: Following effect of rolling force when a square wave signal is input. (a) Operation side. (b) Drive side.

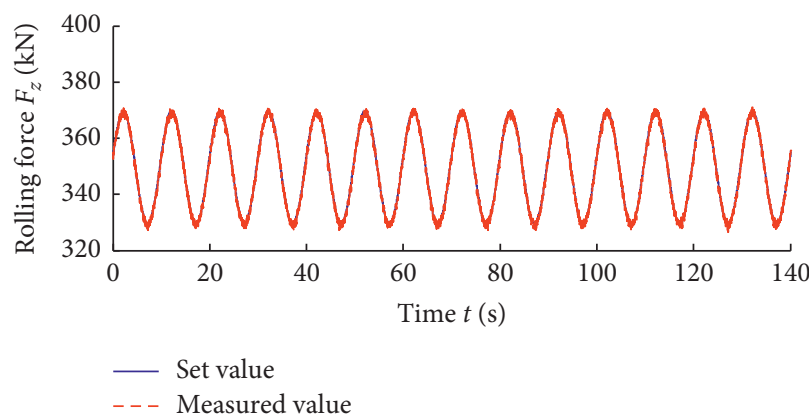

(a)

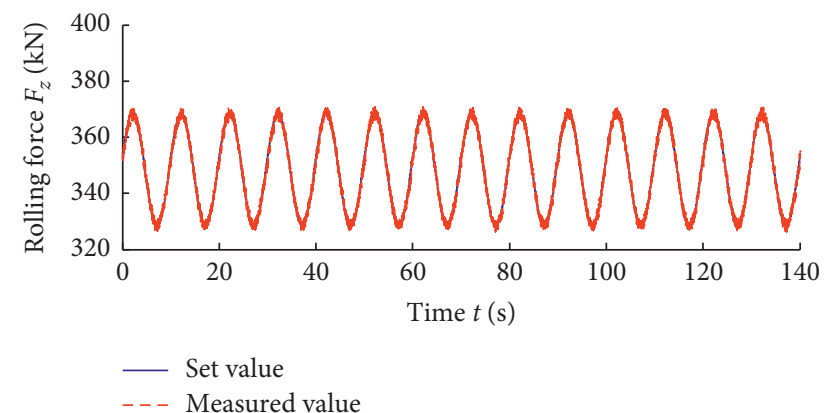

(b)

FIgURE 13: Following effect of rolling force when a sine signal is input. (a) Operation side. (b) Drive side.

signal acquisition scheme, the change of $K_{p}$ is mainly reflected by the variation of the proportional coefficient of controller. The change of $p_{L}$ is mirrored by changing the rolling force. Then, through feature extraction and analysis for system state signals under various working conditions, the influences of the aforementioned different factors on system vibration are explored.

The dynamic tests are carried out according to the various working conditions set up as below. Meanwhile, the vibration responses of the load of the HAGC system are collected by the data acquisition system. The sampling frequency is $1 \mathrm{kHz}$.
The proportional coefficient of the controller is changed by adjusting the PID parameters. The setting values of the proportional coefficient of the controller are shown in Table 1.

The setting values of rolling force are represented in Table 2.

6.4. Analysis of Test Results. When the proportional coefficient of controller is changed, the variation curve of vibration severity of the load of the HAGC system is displayed in Figure 14. It can be seen that, with the increase of the 
TABle 1: Proportional coefficient of controller.

\begin{tabular}{lllllll}
\hline Name & \multicolumn{6}{c}{ Proportional coefficient of controller } \\
\hline Value & 0.1 & 0.15 & 0.2 & 0.25 & 0.3 & 0.35 \\
\hline
\end{tabular}

TABLE 2: Rolling force.

\begin{tabular}{lllllllllll}
\hline Name & \multicolumn{10}{c}{ Rolling force $(\mathrm{kN})$} \\
\hline Value & 200 & 280 & 360 & 440 & 520 & 600 & 680 & 760 & 840 & 920 \\
\hline
\end{tabular}

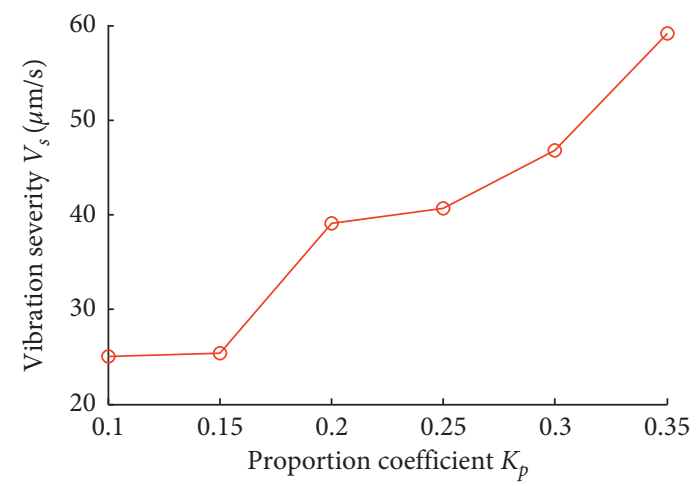

Figure 14: Variation curve of vibration severity under different proportion coefficient.

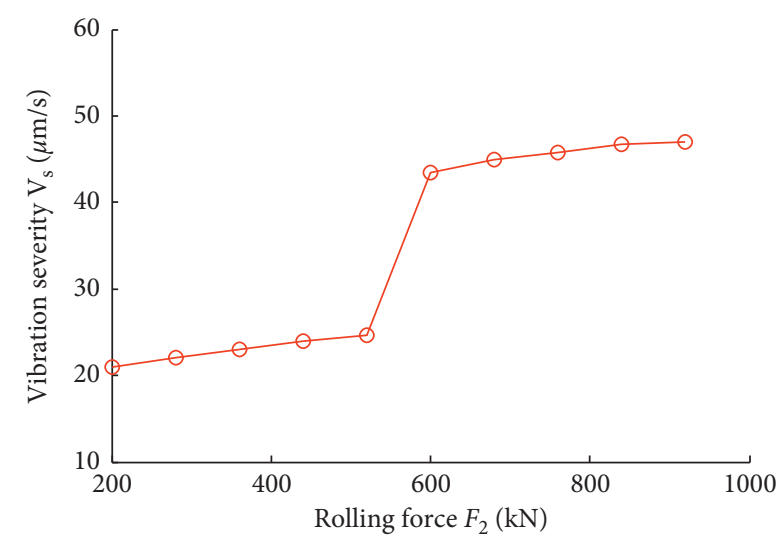

FIGURE 15: Variation curve of vibration severity under different roll force.

proportional coefficient $K_{p}$ of controller, the vibration severity of the load of the HAGC system gradually increases. It means that as $K_{p}$ increases, the vibration intensity of the HAGC system will increase, and the system will be likely to be unstable. Therefore, if the magnitude of the proportionality coefficient $K_{p}$ is appropriately controlled, it is beneficial to the stability of the system. The result reflects the effect of the gain coefficient, which is consistent with the theoretically derived law of the influence of the gain coefficient on the system instability.
When rolling force changes, the variation curve of vibration severity of load of HAGC system is represented in Figure 15. It can be found that with the increase of rolling force, the vibration severity of the load of the HAGC system increases gradually. It indicates that the vibration strength of the HAGC system will augment with the increase of rolling force. This result reflects the effect of the operating pressure $p_{L}$, which shows agreement with the influence of $p_{L}$ on the system stability derived from the instability condition.

\section{Conclusions}

In this paper, aiming at each component of the HAGC system, the mathematical models were established. In accordance with the syntagmatic relation of each element, the incremental transfer model of the key PCL system in HAGC was deduced. Furthermore, according to the deduced information transfer relation, the transfer block diagram of the perturbation of PCL system was instituted. Moreover, in order to derive the absolute stability condition and instability condition, the Popov frequency criterion was employed. The instability conditions of the HAGC system under PCL control were obtained under two working conditions, that is, when the spool displacement of servo valve is positive and negative, respectively. Furthermore, the derived instability conditions of the HAGC system were verified by experiments under various working conditions. The main factors often change in practical working process such as the proportional coefficient $K_{p}$ of controller and the load pressure $p_{L}$. The influences of main factors on system vibration were explored. The results indicate that the vibration strength of the HAGC system will augment with the increase of main factors, which is consistent with the derived instability condition. The research results lay a theoretical basis for the investigation on the instability mechanism of the HAGC system.

The study can provide an essential foundation for further exploration of the oscillation traceability and suppression of the HAGC system. Moreover, it can provide theoretical reference for the instability condition derivation of electrohydraulic servo system in other fields.

\section{Data Availability}

The data that support the findings of this study are available from the corresponding author upon reasonable request.

\section{Conflicts of Interest}

The authors declare no conflicts of interest.

\section{Acknowledgments}

This work was supported by the National Natural Science Foundation of China (51805214 and 51875498), the National Key Research and Development Program of China (2020YFC1512402 and 2019YFB2005204), the China Postdoctoral Science Foundation (2019M651722), the Postdoctoral Science Foundation of Zhejiang Province (ZJ2020090), the Ningbo Natural Science Foundation (202003N4034), the 
Open Foundation of the State Key Laboratory of Fluid Power and Mechatronic Systems (GZKF-201905), the Fundamental Research Funds for the Provincial Universities of Hebei (JQN2019004), the Postdoctoral Science Foundation of Hebei Province (B2020003033), the Applied Basic Research Project of Tangshan (20130211b), and the Youth Talent Development Program of Jiangsu University.

\section{References}

[1] S. Ye, J. Zhang, B. Xu, L. Hou, J. Xiang, and H. Tang, “A theoretical dynamic model to study the vibration response characteristics of an axial piston pump," Mechanical Systems and Signal Processing, vol. 150, Article ID 107237, 2021.

[2] S. Tang, S. Yuan, and Y. Zhu, "Data preprocessing techniques in convolutional neural network based on fault diagnosis towards rotating machinery," IEEE Access, vol. 8, pp. 149487-149496, 2020.

[3] S. Ye, J. Zhang, B. Xu, S. Zhu, J. Xiang, and H. Tang, “Theoretical investigation of the contributions of the excitation forces to the vibration of an axial piston pump," Mechanical Systems and Signal Processing, vol. 129, pp. 201-217, 2019.

[4] S. Wu, L. Wang, Y. Shao, and Y. Yuan, "Vibration characteristic analysis of twenty-high rolling mill with local defect on roll surface based on the time-varying contact stiffness," Engineering Failure Analysis, vol. 42, no. 5, pp. 297-310, 2014.

[5] Y. Shao, X. Deng, Y. Yuan, C. K. Mechefske, and Z. Chen, "Characteristic recognition of chatter mark vibration in a rolling mill based on the non-dimensional parameters of the vibration signal," Journal of Mechanical Science and Technology, vol. 28, no. 6, pp. 2075-2080, 2014.

[6] E. Brusa and L. Lemma, "Numerical and experimental analysis of the dynamic effects in compact cluster mills for cold rolling," Journal of Materials Processing Technology, vol. 209, no. 5, pp. 2436-2445, 2009.

[7] S. Tang, S. Yuan, and Y. Zhu, "Deep learning-based intelligent fault diagnosis methods toward rotating machinery," IEEE Access, vol. 8, no. 1, pp. 9335-9346, 2020.

[8] S. Wu, Y. Shao, L. Wang, Y. Yuan, and C. K. Mechefske, "Relationship between chatter marks and rolling force fluctuation for twenty-high roll mill," Engineering Failure Analysis, vol. 55, pp. 87-99, 2015.

[9] S. N. Tang, Y. Zhu, W. Li, and J. X. Cai, "Status and prospect of research in preprocessing methods for measured signals in mechanical systems," Journal of Drainage and Irrigation Machinery Engineering, vol. 37, no. 9, pp. 822-828, 2019.

[10] S. Tang, S. Yuan, and Y. Zhu, "Convolutional neural network in intelligent fault diagnosis toward rotatory machinery," IEEE Access, vol. 8, no. 1, pp. 86510-86519, 2020.

[11] P. A. Meehan, "Vibration instability in rolling mills: modeling and experimental results," Journal of Vibration and Acoustics, vol. 124, no. 2, pp. 221-228, 2002.

[12] M. R. Niroomand, M. R. Forouzan, and M. Salimi, "Theoretical and experimental analysis of chatter in tandem cold rolling mills based on wave propagation theory," ISIJ International, vol. 55, no. 3, pp. 637-646, 2015.

[13] S. Kapil, P. Eberhard, and S. K. Dwivedy, "Dynamic analysis of cold-rolling process using the finite-element method," Journal of Manufacturing Science and Engineering, vol. 138, no. 4, Article ID 041002, 2016.

[14] X. Fan, Y. Zang, and K. Jin, "Research on strip hysteretic behavior and mill vertical vibration system nonlinear dynamics," Applied Physics A, vol. 122, no. 10, p. 877, 2016.
[15] Y. Zhang, X. Yan, and Q. Lin, "Characteristic of torsional vibration of mill main drive excited by electromechanical coupling," Chinese Journal of Mechanical Engineering, vol. 29, no. 1, pp. 180-187, 2016.

[16] L. Zeng, Y. Zang, and Z. Gao, "Multiple-modal-coupling modeling and stability analysis of cold rolling mill vibration," Shock and Vibration, vol. 2016, Article ID 2347386, 26 pages, 2016.

[17] C.-y. Wang, Y.-b. Jiang, J.-x. Xie, S. Xu, D.-j. Zhou, and X.-j. Zhang, "Formation mechanism and control of aluminum layer thickness fluctuation in embedded aluminum-steel composite sheet produced by cold roll bonding process," Transactions of Nonferrous Metals Society of China, vol. 27, no. 5, pp. 1011-1018, 2017.

[18] J. L. Huang, Y. Zang, Z. Y. Gao, and L. Q. Zeng, "Influence of asymmetric structure parameters on rolling mill stability," Journal of Vibroengineering, vol. 19, no. 7, pp. 4840-4853, 2017.

[19] J. Ji, "Stability of the coupled vibrations of work roll and strip in cold rolling process," Proceedings of the Institution of Mechanical Engineers, Part B: Journal of Engineering Manufacture, vol. 231, no. 7, pp. 1169-1181, 2017.

[20] X. Lu, J. Sun, G. Li, Q. Wang, and D. Zhang, "Dynamic analysis of vibration stability in tandem cold rolling mill," Journal of Materials Processing Technology, vol. 272, pp. 4757, 2019.

[21] X. Lu, J. Sun, G. Li, Z. Wang, and D. Zhang, "Stability analysis of a nonlinear coupled vibration model in a tandem cold rolling mill," Shock and Vibration, vol. 2019, Article ID 4358631, 14 pages, 2019.

[22] Z. Chen, K. T. Tse, K. C. S. Kwok, A. Kareem, and B. Kim, "Measurement of unsteady aerodynamic force on a galloping prism in a turbulent flow: A hybrid aeroelastic-pressure balance," Journal of Fluids and Structures, vol. 102, Article ID 103232, 2021.

[23] C. Mannini, A. M. Marra, T. Massai, and G. Bartoli, "Interference of vortex-induced vibration and transverse galloping for a rectangular cylinder," Journal of Fluids and Structures, vol. 66, pp. 403-423, 2016.

[24] Z. Chen and K. T. Tse, "Identification of physical nonlinearities of a hybrid aeroelastic-pressure balance," Nonlinear Dynamics, vol. 98, no. 1, pp. 95-111, 2019.

[25] Y. Wang, F. Zhang, and S. Yuan, "Effect of unrans and hybrid rans-les turbulence models on unsteady turbulent flows inside a side channel pump," ASME Journal of Fluids Engineering, vol. 142, no. 6, Article ID 061503, 2020.

[26] F. Zhang, D. Appiah, F. Hong et al., "Energy loss evaluation in a side channel pump under different wrapping angles using entropy production method," International Communications in Heat and Mass Transfer, vol. 113, Article ID 104526, 2020.

[27] Z. H. Xue, X. Cao, and T. Z. Wang, "Vibration test and analysis on the centrifugal pump," Journal of Drainage and Irrigation Machinery Engineering, vol. 36, no. 6, pp. 472-477, 2018.

[28] J.-Y. Qian, C.-W. Hou, X.-J. Li, and Z.-J. Jin, "Actuation mechanism of microvalves: a review," Micromachines, vol. 11, no. 2, p. 172, 2020.

[29] Z.-j. Jin, C. Qiu, C.-h. Jiang, J.-y. Wu, and J.-y. Qian, "Effect of valve core shapes on cavitation flow through a sleeve regulating valve," Journal of Zhejiang University-Science A, vol. 21, no. 1, pp. 1-14, 2020.

[30] C. Li, K. Liang, W. Zhong, J. Fang, L. Sun, and Y. Zhu, "Electrochemical coupled analysis of a micro piezo-driven 
focusing mechanism," Micromachines, vol. 11, no. 2, p. 216, 2020.

[31] R. Zhang, P. Sun, and Y. Fu, "Dynamic coupling characteristics of valve flow field and valve core movement in reciprocating pump," Journal of Drainage and Irrigation Machinery Engineering, vol. 39, no. 3, pp. 217-223, 2021.

[32] D. Wu, Y. Zheng, H. Xue, Q. Dai, Y. Zhang, and W. Liu, "Pressure pulsation characteristics of axial-flow pump under multiple working conditions," Journal of Drainage and Irrigation Machinery Engineering, vol. 39, no. 3, pp. 244-250, 2021.

[33] C. Wang, W. Shi, X. Wang et al., "Optimal design of multistage centrifugal pump based on the combined energy loss model and computational fluid dynamics," Applied Energy, vol. 187, pp. 10-26, 2017.

[34] C. Wang, X. Chen, N. Qiu, Y. Zhu, and W. Shi, "Numerical and experimental study on the pressure fluctuation, vibration, and noise of multistage pump with radial diffuser," Journal of the Brazilian Society of Mechanical Sciences and Engineering, vol. 40, no. 10, p. 481, 2018.

[35] W. Li, E. Li, L. Ji, L. Zhou, W. Shi, and Y. Zhu, "Mechanism and propagation characteristics of rotating stall in a mixedflow pump," Renewable Energy, vol. 153, pp. 74-92, 2020.

[36] L. Bai, L. Zhou, X. P. Jiang, Q. L. Pang, and D. X. Ye, "Vibration in a multistage centrifugal pump under varied conditions," Shock and Vibration, vol. 2019, Article ID 2057031, 9 pages, 2019.

[37] L. Zhou, W. Wang, J. Hang, W. Shi, H. Yan, and Y. Zhu, "Numerical investigation of a high-speed electrical submersible pump with different end clearances," Water, vol. 12, no. 4, p. 1116, 2020.

[38] G. Peng, X. Huang, L. Zhou, G. Zhou, and H. Zhou, "Solidliquid two-phase flow and wear analysis in a large-scale centrifugal slurry pump," Engineering Failure Analysis, vol. 114, Article ID 104602, 2020.

[39] L. Zhou, K. Deshpande, X. Zhang, and R. K. Agarwal, "Process simulation of chemical looping combustion using aspen plus for a mixture of biomass and coal with various oxygen carriers," Energy, vol. 195, Article ID 116955, 2020.

[40] S. Mobayen and F. Tchier, "Composite nonlinear feedback control technique for master/slave synchronization of nonlinear systems," Nonlinear Dynamics, vol. 87, no. 3, pp. 1-17, 2017.

[41] S. Mobayen, "Adaptive global terminal sliding mode control scheme with improved dynamic surface for uncertain nonlinear systems," International Journal of Control, Automation and Systems, vol. 16, no. 4, pp. 1692-1700, 2018.

[42] S. Mobayen, "A novel global sliding mode control based on exponential reaching law for a class of underactuated systems with external disturbances," Journal of Computational and Nonlinear Dynamics, vol. 11, Article ID 021011, 2016.

[43] B. Zhang, W. Wei, P. Qian et al., "Research on the control strategy of hydraulic shaking table based on the structural flexibility,” IEEE Access, vol. 7, pp. 43063-43075, 2019.

[44] C. Hua and C. X. Yu, "Controller design for cold rolling mill HAGC system with measurement delay perturbation," Journal of Mechanical Engineering, vol. 50, no. 20, pp. 46-53, 2014.

[45] X. Liu, Y. Zang, Z. Gao, and L. Zeng, "Time delay effect on regenerative chatter in tandem rolling mills," Shock and Vibration, vol. 2016, Article ID 4025650, 15 pages, 2016.

[46] S. Ding and W. X. Zheng, "Controller design for nonlinear affine systems by control Lyapunov functions," Systems \& Control Letters, vol. 62, no. 10, pp. 930-936, 2013.
[47] L. Liu, S. H. Ding, L. Ma, and H. B. Sun, "A novel secondorder sliding mode control based on the Lyapunov method," Transactions of the Institute of Measurement and Control, vol. 41, no. 4, 2018.

[48] J. Zhang, "Integral barrier Lyapunov functions-based neural control for strict-feedback nonlinear systems with multiconstraint," International Journal of Control, Automation and Systems, vol. 16, no. 4, pp. 2002-2010, 2018.

[49] J. Zhang, G. S. Li, Y. H. Li, and X. K. Dai, "Barrier Lyapunov functions-based localized adaptive neural control for nonlinear systems with state and asymmetric control constraints," Transactions of the Institute of Measurement and Control, vol. 41, no. 6, 2019.

[50] M. Saeki, N. Wada, and S. Satoh, "Stability analysis of feedback systems with dead-zone nonlinearities by circle and Popov criteria," Automatica, vol. 66, pp. 96-100, 2016.

[51] L. Xia and H. Jiang, "An electronically controlled hydraulic power steering system for heavy vehicles," Advances in Mechanical Engineering, vol. 8, no. 11, pp. 1-11, 2016.

[52] Q. Bi, S. Li, J. Kurths, and Z. Zhang, "The mechanism of bursting oscillations with different codimensional bifurcations and nonlinear structures," Nonlinear Dynamics, vol. 85, no. 2, pp. 993-1005, 2016.

[53] Y. Zhu, S. Tang, L. Quan, W. Jiang, and L. Zhou, "Extraction method for signal effective component based on extremepoint symmetric mode decomposition and Kullback-Leibler divergence," Journal of the Brazilian Society of Mechanical Sciences and Engineering, vol. 41, no. 2, p. 100, 2019.

[54] X. Yuan, X. Zhu, C. Wang, and L. Zhang, "Research on theoretical model of dynamic bulk modulus of gas-containing hydraulic oil," IEEE Access, vol. 7, pp. 178413-178422, 2019.

[55] Y. Zhu, P. Qian, S. Tang, W. Jiang, W. Li, and J. Zhao, "Amplitude-frequency characteristics analysis for vertical vibration of hydraulic AGC system under nonlinear action," AIP Advances, vol. 9, no. 3, Article ID 035019, 2019.

[56] Y. Zhu, S. Tang, C. Wang, W. Jiang, X. Yuan, and Y. Lei, "Bifurcation characteristic research on the load vertical vibration of a hydraulic automatic gauge control system," Processes, vol. 7, no. 10, p. 718, 2019.

[57] Y. Z. Liu and L. Q. Chen, Nonlinear Vibration, Higher Education Press, Beijing, China, 2001.

[58] Y. Zhu, S. Tang, C. Wang, W. Jiang, J. Zhao, and G. Li, "Absolute stability condition derivation for position closedloop system in hydraulic automatic gauge control," Processes, vol. 7, no. 10, p. 766, 2019.

[59] W. J. Ding, Self-Excited Vibration, Vol. 84, Tsinghua University Press, Beijing, China, 2009. 